\title{
Massive donor transfusion potentially increases recipient mortality after lung transplantation
}

\author{
Catherine F. Borders, BA, ${ }^{a}$ Yoshikazu Suzuki, MD, ${ }^{a}$ Jared Lasky, BA, ${ }^{\mathrm{a}}$ Christian Schaufler, BA, ${ }^{\mathrm{a}}$ \\ Djamila Mallem, MA, ${ }^{a}$ James Lee, MD, ${ }^{b}$ Kevin Carney, NP, ${ }^{c}$ Scarlett L. Bellamy, ScD, ${ }^{d}$ \\ Christian A. Bermudez, MD, ${ }^{a}$ A. Russell Localio, JD, MA, MPH, MS, PhD, ${ }^{\mathrm{d}}$ \\ Jason D. Christie, MD, MSCE, ${ }^{\text {,d }}$ Joshua M. Diamond, MD, MSCE, ${ }^{\mathrm{b}}$ and Edward Cantu, MD, MSCE ${ }^{\mathrm{a}}$
}

\section{ABSTRACT}

Objective: Donor blood transfusion has been identified as a potential risk factor for primary graft dysfunction and by extension early mortality. We sought to define the contributing risk of donor transfusion on early mortality for lung transplant.

Methods: Donor and recipient data were abstracted from the Organ Procurement and Transplantation Network database updated through June 30, 2014, which included 86,398 potential donors and 16,255 transplants. Using the United Network for Organ Sharing 4-level designation of transfusion (no blood, 1-5 units, 6-10 units, and $>10$ units, massive), we analyzed all-cause mortality at 30-days with the use of logistic regression adjusted for confounders (ischemic time, donor age, recipient diagnosis, lung allocation score and recipient age, and recipient body mass index). Secondary analyses assessed 90-day and 1-year mortality and hospital length of stay.

Results: Of the 16,255 recipients transplanted, $8835(54.35 \%)$ donors received at least one transfusion. Among those transfused, $1016(6.25 \%)$ received a massive transfusion, defined as $>10$ units. Those donors with massive transfusion were most commonly young trauma patients. After adjustment for confounding variables, donor massive transfusion was associated significantly with an increased risk in 30-day $(P=.03)$ and 90 -day recipient mortality $(P=.01)$ but not 1 -year mortality $(P=.09)$. There was no significant difference in recipient length of stay or hospital-free days with respect to donor transfusion.

Conclusions: Massive donor blood transfusion ( $>10$ units) was associated with early recipient mortality after lung transplantation. Conversely, submassive donor transfusion was not associated with increased recipient mortality. The mechanism of increased early mortality in recipients of lungs from massively transfused donors is unclear and needs further study but is consistent with excess mortality seen with primary graft dysfunction in the first 90 days posttransplant. (J Thorac Cardiovasc Surg 2017;153:1197-203)

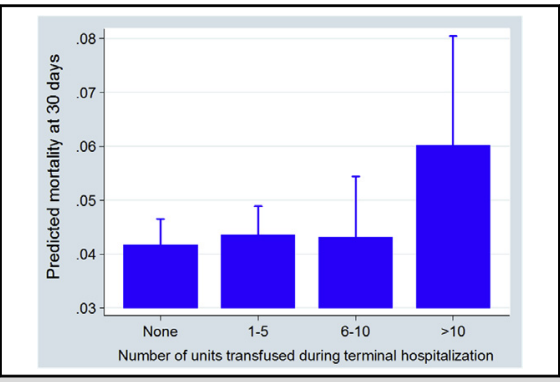

30-day mortality risk of transplant recipients stratified by amount of blood transfused.

\section{Central Message}

Only massive donor transfusion ( $>10$ units) should be considered a risk factor for early mortality and use should be considered depending on individual centers risk tolerance.

\section{Perspective}

Donor transfusion is considered a risk factor for primary graft dysfunction and death. In this study, only massive donor transfusion $(>10$ units) was associated with increased risk in perioperative mortality. This finding suggests donors with submassive transfusion alone should be used for transplant and massively transfused donors should be considered and transplanted depending on individual centers risk tolerance.

See Editorial Commentary page 1204.

\footnotetext{
From the ${ }^{\mathrm{a}}$ Division of Cardiovascular Surgery, ${ }^{\mathrm{b}}$ Pulmonary, Allergy, and Critical Care Division, and ${ }^{\mathrm{d}}$ Center for Clinical Epidemiology and Biostatistics, University of Pennsylvania School of Medicine; and ${ }^{\mathrm{c}}$ Transplant Institute, University of Pennsylvania, Philadelphia, Pa.

Supported in part by Health Resources and Services Administration contract 234-2005-370011C. Investigator support was provided by the National Institutes of Health and Robert Wood Johnson Foundation through several mechanisms: HL087115, HL081619, HL096845, HL115354, HL121406, HL114626, HL116656, RWJ11642, and HL090021. The content is the responsibility of the authors alone and does not necessarily reflect the views or policies of the Department of Health and Human Services, nor does mention of trade names, commercial products, or organizations imply endorsement by the US government.
}

Drs Diamond and Cantu contributed equally to this work.

Received for publication Nov 20, 2015; revisions received Nov 18, 2016; accepted for publication Dec 4, 2016; available ahead of print Jan 8, 2017.

Address for reprints: Edward Cantu, MD, MSCE, Division of Cardiovascular Surgery, University of Pennsylvania Perelman School of Medicine, 3400 Spruce St, 6 Silverstein Pavilion, Philadelphia, PA 19104 (E-mail: edward.cantu@uphs. upenn.edu).

$0022-5223 / \$ 36.00$

Copyright (C) 2016 by The American Association for Thoracic Surgery

http://dx.doi.org/10.1016/j.jtcvs.2016.12.006 


$$
\begin{aligned}
& \text { Abbreviations and Acronyms } \\
& \begin{aligned}
\text { CI } & =\text { confidence interval } \\
\text { LAS } & =\text { lung allocation score } \\
\text { OR } & =\text { odds ratio } \\
\text { PGD } & =\text { primary graft dysfunction } \\
\text { TRALI } & =\text { transfusion-related acute lung injury } \\
\text { UNOS } & =\text { United Network for Organ Sharing }
\end{aligned}
\end{aligned}
$$

Scanning this QR code will take you to supplemental figures, tables, and video for this article.

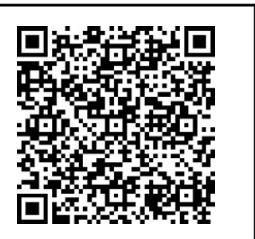

Lung transplantation is an established therapeutic option for select patients with end-stage lung disease. There is a large discrepancy, however, between the number of suitable lung donors for transplant and the number of patients on the waiting list, resulting in many potential recipients dying on the waiting list or being removed as the result of clinical decline. ${ }^{1}$ Given this challenge, there is increasing pressure to expand the donor pool. Compared with other solid organs, however, overall survival after lung transplantation is limited, and efforts to reduce primary graft dysfunction (PGD) risk may cause reticence with respect to certain lung donors, thus potentially further reducing the donor pool. In the United States, only about $20 \%$ of potential donor lungs are used for transplant. ${ }^{2,3}$

Donor blood transfusion is considered by many as a risk factor for lung injury and potential PGD; however, there is little published evidence available within the lung transplant literature. An association with PGD and blood product transfusion in lung transplant recipients has been established, but the mechanism has yet to be elucidated. ${ }^{4}$ Within the critical care literature, significant blood transfusion can cause transfusion-related acute lung injury (TRALI), which is similar to PGD in clinical and radiographic presentation. ${ }^{5}$ Whether the initiation of the inflammatory cascade responsible for reperfusion injury of PGD in the lung could result from the lung injury seen in donor TRALI has not been established. ${ }^{6}$ PGD is the major cause of early mortality, and thus important effects of donor transfusion may be reflected in excess mortality risk. Because of the absence of literature available to guide decision making with respect to donor transfusion, we initiated this study to define donor blood product transfusion risk for posttransplant mortality. We also sought to evaluate the comparative use of blood transfusions in organ donors who were not used for transplant because blood transfusion may disproportionately decrease donor suitability.

\section{METHODS \\ Data Source}

After obtaining institutional review board approval, we queried the United Network for Organ Sharing (UNOS) database for lung transplant recipients and their respective donors from March 20, 1996, through June 30, 2014. Analysis included a total of 86,398 lung donor offers, which resulted in 16,255 lung transplants. None were excluded.

\section{Exposure Variable}

In the UNOS database, donor transfusion exposure was defined and categorized on the basis of the receipt of blood transfusions during the terminal hospitalization period: no blood $(\mathrm{n}=7420), 1$ to 5 units $(\mathrm{n}=6197), 6$ to 10 units $(\mathrm{n}=1622)$, and greater than 10 units (massive) $(\mathrm{n}=1016)$.

\section{Outcome Definition}

The primary outcome of interest was all-cause 30-day mortality. We evaluated 90-day and 1-year mortality and length of stay as secondary outcomes. We examined both the overall length of hospital stay, the length of stay conditional on 30-day survival, and hospital-free days to account for early deaths posttransplant.

\section{Statistical Analysis}

Categorical variables are expressed as percentages and continuous variables as means ( \pm standard deviations) when appropriate. Logistic regression was used to analyze the unadjusted all-cause mortality at 30 days and 90 days among the different donor groups. Because many factors contribute to risk and decisions for transplant, we used a multivariable logistic model to control for confounders. Confounding variables were chosen based on the strength of association and consistency of findings with risk of post-operative mortality in the literature. ${ }^{7,8}$ This included ischemic time ( $>6$ hours), donor age ( $>40$ years), recipient diagnosis, lung allocation score (LAS) score, and recipient age ( $>60$ years), recipient body mass index $(>30)$, and transplant era (binary or ordinal variable). Donor mechanism of death was omitted due to collinearity with the frequency of blood transfusions. PGD status was not controlled for in the analysis because it was not available consistently in the UNOS dataset and furthermore is one of the most common causes of death within the first 90 days and as such can be considered to be part of the causal pathway. To further evaluate the association of transfusion and mortality, inverse probability weighting using a propensity score (probability of treatment assignment conditional on observed baseline characteristics used in logistic model) sensitivity analysis was performed. Logistic regression was used to evaluate early mortality. Inverse probability weighted Kaplan-Meyer was used for survival analysis.'

Results of logistic regression models are displayed as odds ratios (ORs) and $95 \%$ confidence intervals (CIs). Predictive margins were used to compare the risk of mortality per transfusion level using the "margins" command in STATA (StataCorp LP, College Station, Tex). Length of stay values are presented as means ( \pm standard deviation). A 2-sample $t$ test was used to determine whether differences among groups were significant. The level of statistical significance was $P<.05$. All statistical analyses were conducted with STATA 12.0 software (StataCorp LP).

\section{RESULTS \\ Patient Demographics}

Recipient and donor demographics are detailed in Table 1. Donors tended to be male $(59.67 \%)$, slightly overweight $(25.55 \pm 5.28 \mathrm{~kg})$, and have a history of cigarette use $(11.4 \%)$. The most common mechanism of death was trauma $(48.07 \%)$ and most were younger than 40 years 
TABLE 1. Donor and recipient demographics

\begin{tabular}{|c|c|c|c|c|c|}
\hline \multirow[b]{2}{*}{ Characteristics } & \multirow[b]{2}{*}{$\begin{array}{c}\text { Overall population } \\
(\mathrm{n}=\mathbf{1 6 , 2 5 5})\end{array}$} & \multicolumn{4}{|c|}{ Number of transfusions (units) } \\
\hline & & $\begin{array}{c}0 \\
(n=7420)\end{array}$ & $\begin{array}{c}1-5 \\
(n=6197)\end{array}$ & $\begin{array}{c}6-10 \\
(n=1622)\end{array}$ & $\begin{array}{c}>10 \\
(\mathbf{n}=1016)\end{array}$ \\
\hline \multicolumn{6}{|l|}{ Donor } \\
\hline Age, y, mean (SD) & $33.57(14.60)$ & $37.51(14.61)$ & $31.76(14.25)$ & $27.44(12.48)$ & $25.67(10.48)$ \\
\hline Female, $\%$ & 40.33 & 41.64 & 43.42 & 28.91 & 30.02 \\
\hline \multicolumn{6}{|l|}{ Ethnicity, \% } \\
\hline White & 61.93 & 64.37 & 59.92 & 61.59 & 56.99 \\
\hline Black & 19.13 & 18.22 & 20.14 & 18.19 & 21.06 \\
\hline Hispanic & 15.17 & 13.45 & 16.22 & 16.89 & 18.6 \\
\hline Asian & 2.41 & 2.56 & 2.34 & 1.97 & 2.46 \\
\hline American Indian & 0.39 & 0.4 & 0.45 & 0.12 & 0.39 \\
\hline Native Hawaiian & 0.22 & 0.28 & 0.18 & 0.25 & - \\
\hline Multiracial & 0.74 & 0.71 & 0.76 & 0.99 & 0.49 \\
\hline Smoking history, $\%$ & 11.4 & 13.1 & 10.8 & 8.1 & 7.9 \\
\hline BMI, mean (SD) & $25.55(5.28)$ & $26.17(5.46)$ & $25.10(5.25)$ & $24.71(4.59)$ & $25.17(4.60)$ \\
\hline \multicolumn{6}{|l|}{ Mode of death, $\%$} \\
\hline Anoxia & 13.79 & 19.74 & 10.78 & 3.51 & 5.02 \\
\hline CVA & 34.9 & 51.09 & 27.71 & 7.34 & 4.53 \\
\hline Trauma & 48.07 & 25.18 & 58.43 & 87.73 & 88.78 \\
\hline CNS tumor & 0.8 & 1.01 & 0.74 & 0.43 & 0.2 \\
\hline Other & 2.44 & 2.98 & 2.34 & 0.99 & 1.48 \\
\hline \multicolumn{6}{|l|}{ Recipient } \\
\hline Age, mean (SD) & $52.98(15.06)$ & $53.62(14.32)$ & $52.26(15.91)$ & $52.92(14.90)$ & $52.74(15.09)$ \\
\hline Female, $\%$ & 41.91 & 41.08 & 44.31 & 38.96 & 37.99 \\
\hline \multicolumn{6}{|l|}{ Ethnicity, \% } \\
\hline White & 83.89 & 84.84 & 82.59 & 83.42 & 85.73 \\
\hline Black & 8.32 & 7.99 & 9 & 8.08 & 6.89 \\
\hline Hispanic & 5.71 & 5.16 & 6.34 & 5.98 & 5.41 \\
\hline Asian & 1.35 & 1.29 & 1.42 & 1.36 & 1.38 \\
\hline American Indian & 0.31 & 0.3 & 0.39 & 0.18 & 0.2 \\
\hline Native Hawaiian & 0.08 & 0.08 & 0.05 & 0.18 & 0.1 \\
\hline Multiracial & 0.33 & 0.34 & 0.21 & 0.8 & 0.3 \\
\hline BMI, mean (SD) & $24.86(4.97)$ & $24.92(4.90)$ & $24.78(5.06)$ & $24.96(5.02)$ & $24.76(4.79)$ \\
\hline \multicolumn{6}{|l|}{ Diagnosis, $\%$} \\
\hline Obstructive & 32.42 & 32.36 & 31.83 & 34.07 & 34.55 \\
\hline Vascular & 3.52 & 3.41 & 3.83 & 3.09 & 3.15 \\
\hline CF/immunodeficiency & 13.22 & 12.71 & 13.7 & 13.33 & 13.88 \\
\hline Restrictive & 50.84 & 51.62 & 50.64 & 49.51 & 48.43 \\
\hline LAS & $46.53(17.25)$ & $46.96(17.48)$ & $46.44(17.27)$ & $45.85(17.03)$ & $44.89(15.56)$ \\
\hline
\end{tabular}

All comparisons were significant $(P<.05)$ between transfusion groups except for all comparisons within recipient BMI, recipient diagnosis, and a few comparisons within donor BMI (1-5 vs $>10$ or 6-10 vs $>10$ not significant), recipient age (only 0 vs $1-5$ significant) and LAS (only 0 vs $>10$ significant). Based on Organ Procurement and Transplantation Network data as of September 5, 2014. SD, Standard deviation; BMI, body mass index; $C V A$, cerebrovascular accident; $C N S$, central nervous system; $C F$, cystic fibrosis; $L A S$, lung allocation score.

of age (33.57 \pm 14.60 years) at the time of donation. Donors who received massive blood transfusions also tended to be younger, and nearly $90 \%$ suffered from trauma (Figure 1 and Table E1). Most recipients were male $(58.09 \%)$, of normal weight $(24.86 \pm 4.97 \mathrm{~kg})$, and suffered from pulmonary fibrosis $(50.84 \%)$. At the time of transplant, the average LAS score was $46.53 \pm 17.25$, and most recipients were older than 50 years of age $(52.98 \pm 15.06$ years $)$.

\section{Comparison of Donor Offers by Transplant Status}

Of 86,398 total lung donor offers, 16,255 were transplanted $(18.8 \%)$. Of the 16,255 transplanted, 8835 $(54.35 \%)$ donors received at least one unit of blood, and $1016(6.25 \%)$ received a massive blood transfusion whereas $7420(45.65 \%)$ received none. When we compared transplanted with nontransplanted lungs, the distribution of donors by units of blood transfused tended to be similar (Figure 2). 


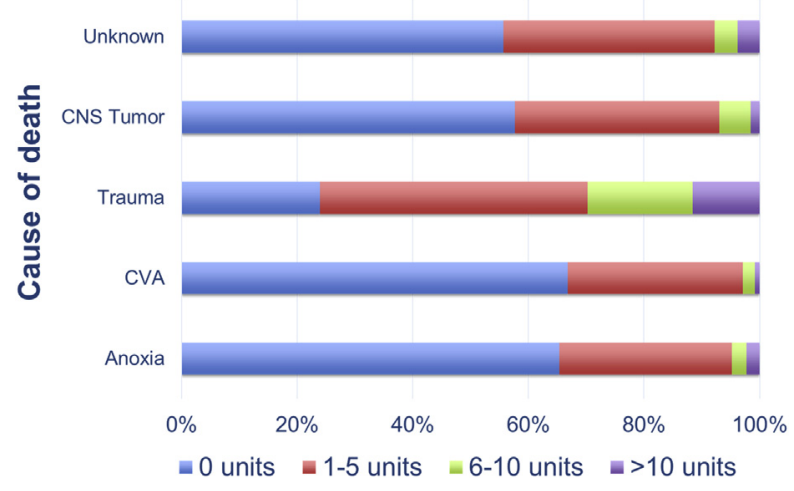

FIGURE 1. Cause of death and number of blood transfusions (units) received. Based on Organ Procurement and Transplantation Network data as of September 5, 2014. CNS, Central nervous system; CVA, cerebrovascular accident.

\section{Risk of Blood Transfusion on 30-Day Mortality}

In unadjusted analyses, massive blood transfusion in organ donors demonstrated a trend for increased risk for 30-day mortality (OR, $1.32 ; \quad 95 \%$ CI, $0.98-1.77$; $P=.064)$ in lung transplant recipients. This trend continued to 90 days but was diminished by 1 year (OR, $1.09 ; 95 \%$ CI, $0.92-1.30 ; P=.98$ ). Survival analysis at 1 year also demonstrated no significant difference between groups $(P=.64)$. After we adjusted for confounding variables, massive donor blood transfusion was associated independently with increased risk of 30-day mortality (OR, 1.41; 95\% CI, 1.03-1.92; $P=.03$ ) (Figure 3 and
Table 2). This risk remained elevated at 90 days (OR, $1.36 ; 95 \%$ CI, $1.06-1.73 ; P=.01)$. The predicted mortality of each transfusion category adjusted for confounders demonstrated significant increase risk of mortality only for recipients who receive organs from massively transfused donors $(P=.03)$. This risk remained elevated for 90-day mortality as well (Figure E1). A sensitivity analysis taking into consideration era as a binary (pre/post LAS) or ordinal variable in the model (pre-LAS, 2005-2010, 2011-2014) demonstrated only small changes to the point estimate, CIs, or significance (binary: $1.47[1.01-2.15) P=.046$; ordinal: 1.47 [1.00-2.14) $P=.047$ ). Additional sensitivity analysis evaluating 4 potentially confounding variables (suspected donor pulmonary infection, chest radiograph, and left and right bronchoscopic results) did not substantially change the magnitude or significance of the risk estimates (1.47 [1.001-2.15) $P=.046$ to 1.54 [1.04-2.30) $P=.032$ ). A final sensitivity analysis evaluating blood transfusion risk in donors who died of intracerebral hemorrhage/stroke was performed and demonstrated a similar mortality risk with OR 1.39 and 1.47 for 30- and 90-day mortality, respectively. Adjusted survival analysis at 1 year did not reach significance in Cox regression model $(P=.09)$ (Figure E2 and Table E2).

\section{Length of Stay}

There was no significant difference in length of stay with respect to transfusion. This remained true whether the

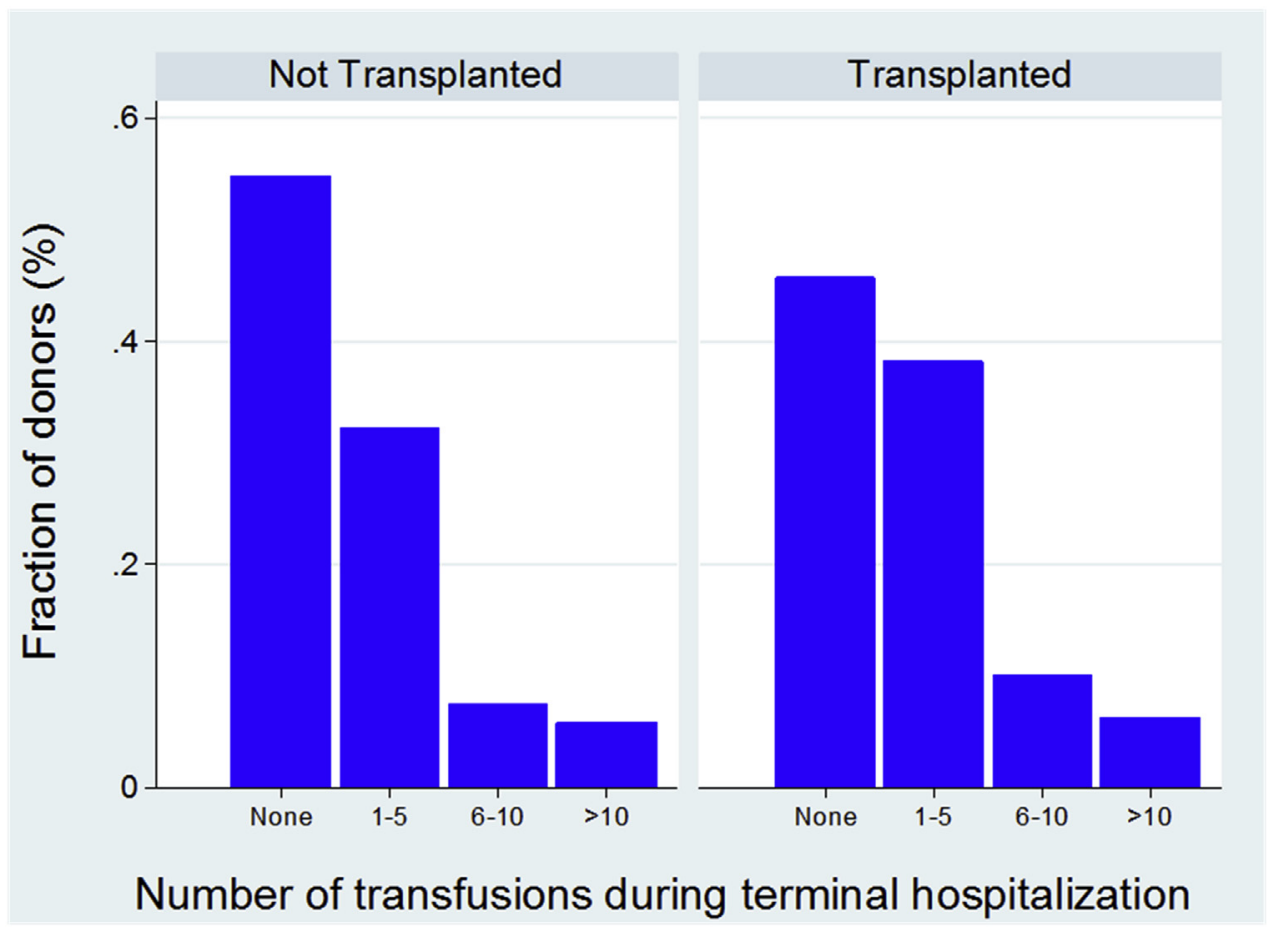

FIGURE 2. Displays comparative use of blood transfusions in lung donors that have received (0) no blood, (1) 1 to 5 units, (2) 6 to 10 units, (3) $>10$ units in both transplanted and discarded lungs. Based on Organ Procurement and Transplantation Network data as of September 5, 2014. 


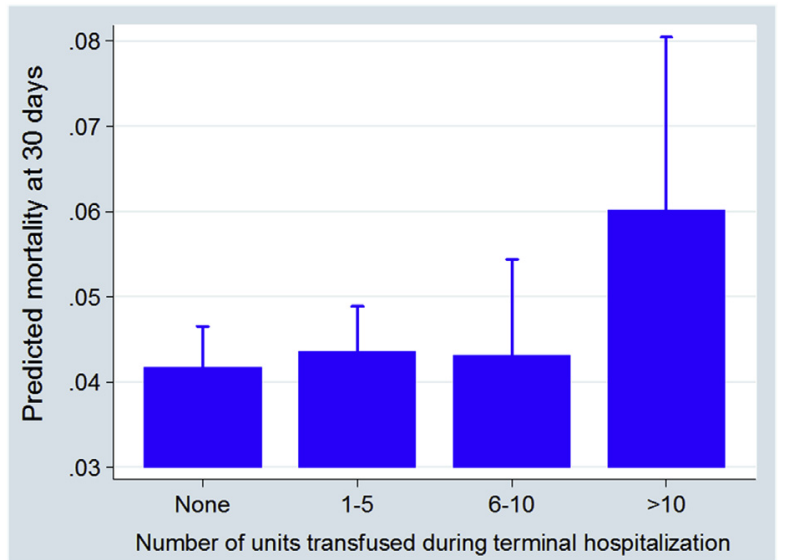

FIGURE 3. 30-day mortality risk. Plots of predicted 30-day mortality risk of transplant recipients when given lungs from donors who have received no blood, 1 to 5 units, 6 to 10 units, and $>10$ units of blood. Bars depict predicted mortality by blood transfusion with $95 \%$ confidence intervals. Comparisons among groups demonstrated significant difference in risk between the no transfusion group and the $>10$ units group $(P=.03)$, all other comparisons were not significant. Based on Organ Procurement and Transplantation Network data as of September 5, 2014.

analysis was conditioned on 90-day survival or 90-day hospital-free days (Figure 4).

\section{DISCUSSION}

In the current era, there is considerable pressure to maximize the assessment and use of donors for lung transplantation. Perceived risk of perioperative mortality, however, affects donor selection and can influence organ use. Because PGD is a major cause of early mortality posttransplant, ${ }^{10-12}$ acceptable risk for PGD varies between center and by surgeon, and evidence has demonstrated increased risk of lung injury in lung transplant recipients who have received blood transfusions posttransplantation. ${ }^{5}$ Therefore, this study was conducted to define more fully the risk to the recipient associated with blood transfusions in organ donors. We have demonstrated that recipients of lungs from donors who have received massive blood transfusions ( $>10$ units) are independently associated with increased 30- and 90-day all-cause mortality. This risk is still present but attenuated by 1-year, thereby potentially implicating PGD as a likely cause of this early risk.

Given that PGD is a major cause of early mortality ${ }^{10-12}$ and the clinical similarities between PGD and TRALI, ${ }^{5,13,14}$ further studies looking at the cause of recipient death for those who received lungs from donors given massive blood transfusions are warranted. Perhaps a small portion of transplant recipients who have received lungs from donors given more than 10 units of blood and are defined as having PGD actually may have donorderived TRALI. This is plausible, given that TRALI has been hypothesized to be the result of 2 insults, with the first being related to the underlying condition of the patient (surgery or infection) and the second hit being the transfusion of damaging blood products. ${ }^{15}$ In this study,

TABLE 2. ORs for 30-day mortality OR

\begin{tabular}{|c|c|c|c|c|c|c|}
\hline \multirow[b]{2}{*}{ Characteristics } & \multicolumn{2}{|c|}{ Full model } & \multicolumn{2}{|c|}{ Final model } & \multicolumn{2}{|c|}{ Propensity-adjusted model } \\
\hline & OR $(95 \%$ CI $)$ & $P$ value & OR $(95 \%$ CI $)$ & $P$ value & OR $(95 \%$ CI $)$ & $P$ value \\
\hline \multicolumn{7}{|l|}{ Donor variables } \\
\hline \multicolumn{7}{|l|}{ No. transfusions (units) } \\
\hline 0 & Reference & - & Reference & - & Reference & - \\
\hline $1-5$ & $1.04(0.87-1.25)$ & .65 & $1.02(0.86-1.22)$ & .78 & $1.04(0.87-1.26)$ & .66 \\
\hline $6-10$ & $1.11(0.83-1.47)$ & .48 & $1.07(0.81-1.42)$ & .62 & $1.05(0.76-1.44)$ & .79 \\
\hline$>10$ & $1.47(1.10-2.02)$ & .017 & $1.41(1.03-1.92)$ & .03 & $1.54(1.04-2.30)$ & .032 \\
\hline Ischemic time $>6 \mathrm{~h}$ & $1.30(1.10-1.54)$ & .003 & $1.31(1.10-1.54)$ & .002 & - & - \\
\hline Donor age $>40 \mathrm{y}$ & $1.12(0.95,1.33)$ & .18 & - & - & & \\
\hline \multicolumn{7}{|l|}{ Recipient variables } \\
\hline \multicolumn{7}{|l|}{ Diagnostic group* } \\
\hline Obstructive & Reference & - & Reference & - & - & - \\
\hline Vascular & $2.51(1.77-3.57)$ & $<.001$ & $2.55(1.80-3.61)$ & $<.001$ & - & - \\
\hline $\mathrm{CF} /$ immunodeficiency & $0.59(0.41-0.83)$ & .003 & $0.60(0.43-0.85)$ & .004 & - & - \\
\hline Restrictive & $1.23(0.99-1.52)$ & .056 & $1.23(0.99-1.52)$ & .059 & - & - \\
\hline LAS & $1.01(1.01-1.02)$ & $<.001$ & $1.01(1.01-1.02)$ & $<.001$ & - & - \\
\hline Recipient BMI >30 & $1.38(1.13-1.69)$ & .002 & $1.38(1.13-1.69)$ & .002 & - & - \\
\hline Recipient age $>60 y$ & $0.93(0.78-1.10)$ & .38 & - & - & - & - \\
\hline Era & $0.81(0.69-0.96)$ & .016 & $0.81(0.69-0.96)$ & .016 & - & - \\
\hline
\end{tabular}

The full model includes all the variables listed. The final model is optimized using Bayesian information criterion statistic to drop less informative factors. The propensityadjusted model uses all variables listed (ischemic time, donor age, recipient diagnostic group, era, pulmonary infection, chest radiograph result, and right bronchoscopy result and left bronchoscopy result) to weight the effects of transfusion. Based on Organ Procurement and Transplantation Network data as of September 5, 2014. OR, Odds ratio; $C I$, confidence interval; $C F$, cystic fibrosis; $L A S$, lung allocation score; $B M I$, body mass index. *LAS diagnosis categories. 
A

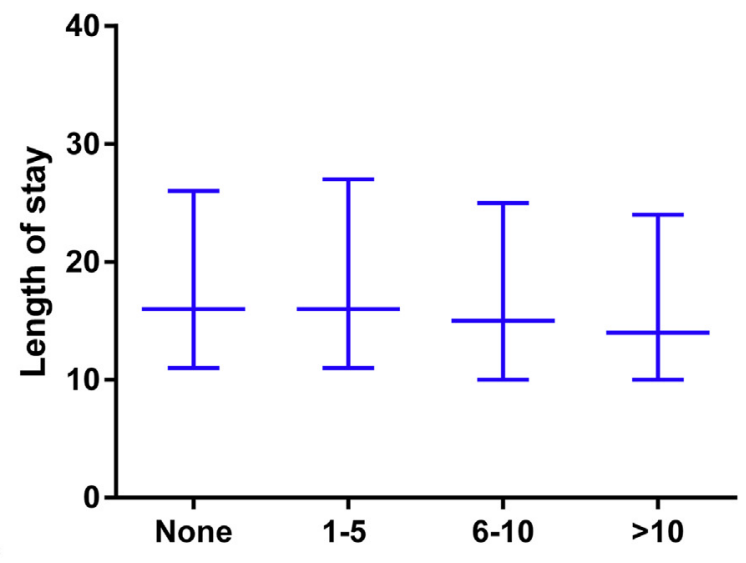

B
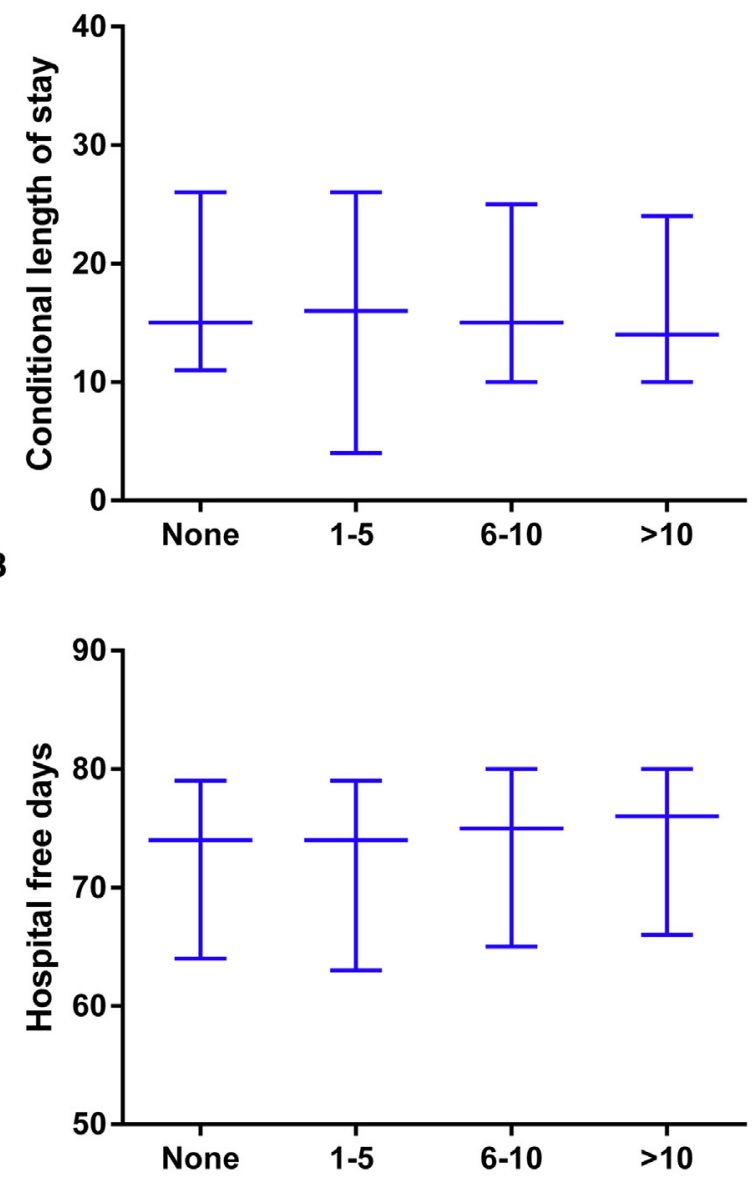

C

\section{Units of Blood Transfused}

FIGURE 4. Length of stay, conditional length of stay, and hospitalfree days. Plots showing the length of stay (A) overall; (B) conditioned on 90-day survival; and (C) hospital-free days in transplant recipients when given lungs from donors who have received no blood, 1 to 5 units, 6 to 10 units, $>10$ units of blood transfused. Lines display medians; error bars indicate interquartile ranges. Based on Organ Procurement and Transplantation Network data as of September 5, 2014.

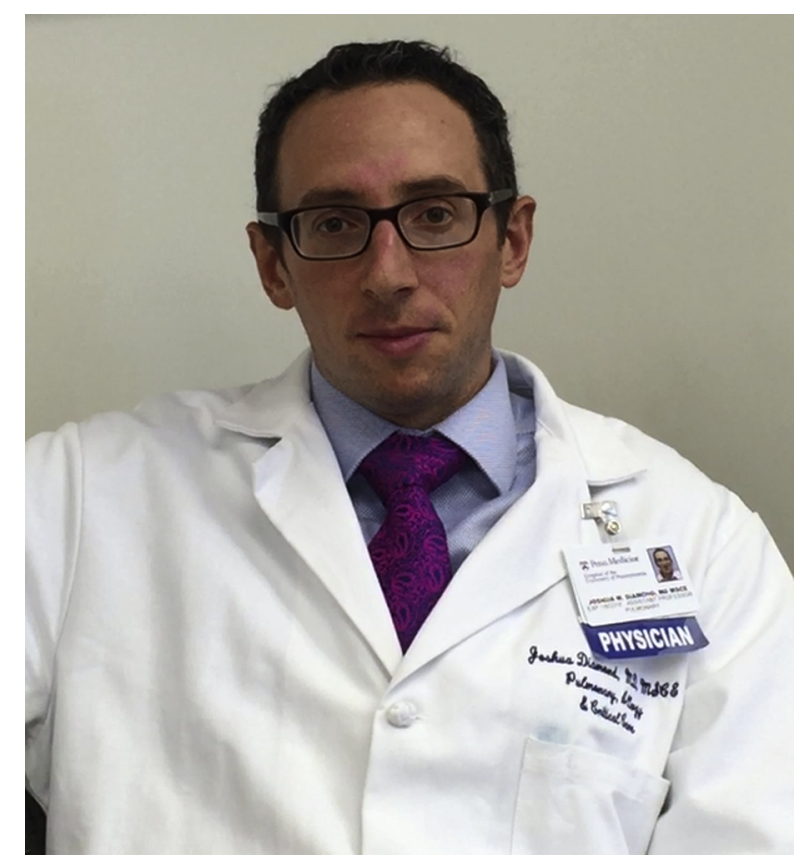

VIDEO 1. Discussion of results by senior authors. Video available at: http://www.jtcvsonline.org/article/S0022-5223(16)31669-5/addons.

massive blood transfusions typically are given to donors who have experienced trauma. It is possible that trauma and massive blood transfusions in donors could be a predisposing clinical condition making the lung prone to further injury after transplantation.

There are several potential limitations to this study. Although we have reported the risks of massive transfusion on mortality using a cohort of transplanted recipients, there is the potential for selection bias by not including massively transfused donors who were not accepted for transplant. Although we cannot predict mortality risk on donors not used for transplant, the distribution of transfusion among untransplanted donors was similar to donors included in our study cohort, which suggests that either transfusion is not necessarily a factor in the decision to use donors or our cohort is representative of all potential donors. Another issue is the inherent limitation of retrospective analysis of an administrative database. As such, we are unable to validate the recorded data, and this dataset does not capture all potential factors that may influence recipient risk or surgical decision making. However, the UNOS data set is used for quality assessment of programs and organ procurement organizations and therefore is audited by those organizations to ensure accurate assessment. It also is possible that decisions for transplant may be influenced by the recipient's severity of illness. To control for this, we used the end match LAS as a surrogate marker of illness severity with the understanding that this variable is not a perfect surrogate. In addition, 
sensitivity analyses including and excluding this variable had minimal impact of risk estimates for massive transfusion and remained independently associated with increased risk. It also should be noted that blood transfusion may be a surrogate marker of trauma or some other unmeasured informative marker that was not captured within this dataset. Should this be the case, it is still helpful to understand this association, although it may not be causal. In addition, approximately $10 \%$ of massively transfused donors died from anoxia and intracranial hemorrhage, raising the question of whether there was unrecorded trauma or exposure misclassification in this subpopulation. It also is possible that intraoperative transfusion may not be captured or accurately reported. Finally, given the ordinal nature of the transfusion variable within the UNOS dataset, it is impossible to define the true inflection point in units of blood that results in increased risk of mortality. Perhaps alterations in the methods of collection of transfusion variables to define preoperative and intraoperative blood transfusion in a continuous fashion could result in precise estimates of risk.

In summary, we have demonstrated that massive blood transfusions ( $>10$ units) of lung donors is associated with a significantly increased 30- and 90-day mortality risk that is not sustained at 1 year. Conversely, submassive transfusion $(<10$ units $)$ is not associated with 30-day, 90-day, or 1-year mortality or length of stay. Taken together, we would recommend using nonmassively transfused donors for transplantation provided there are no other contraindications and selective use of massively transfused donors based on individual centers risk tolerance and experience with early management of PGD.

A video of the senior authors discussing the results is available online (Video 1).

\section{Conflicts of Interest Statement}

Authors have nothing to disclose with regard to commercial support.

\section{References}

1. Naik PM, Angel LF. Special issues in the management and selection of the donor for lung transplantation. Semin Immunopathol. 2011;33:201-10.

2. Christie JD, Edwards LB, Kucheryavaya AY, Benden C, Dipchand AI, Dobbels F, et al. The Registry of the International Society for Heart and Lung Transplantation: 29th adult lung and heart-lung transplant report-2012. J Heart Lung Transplant. 2012;31:1073-86.

3. Valapour M, Paulson K, Smith JM, Hertz MI, Skeans MA, Heubner BM, et al. OPTN/SRTR 2011 Annual Data Report: lung. Am J Transplant. 2013;13(suppl 1):149-77.

4. Christie JD, Shah CV, Kawut SM, Mangalmurti N, Lederer DJ, Sonett JR, et al. Plasma levels of receptor for advanced glycation end products, blood transfusion, and risk of primary graft dysfunction. Am J Respir Crit Care Med. 2009;180:1010-5.

5. Webert KE, Blajchman MA. Transfusion-related acute lung injury. Transfus Med Rev. 2003; 17:252-62.

6. Rizk A, Gorson KC, Kenney L, Weinstein R. Transfusion-related acute lung injury after the infusion of IVIG. Transfusion. 2001;41:264-8.

7. Sekine Y, Waddell TK, Matte-Martyn A, Pierre AF, de Perrot M, Fischer S, et al Risk quantification of early outcome after lung transplantation: donor, recipient, operative, and post-transplant parameters. J Heart Lung Transplant. 2004;23: 96-104.

8. Grimm JC, Valero V III, Magruder JT, Kilic A, Dungan SP, Silhan LL, et al. A novel risk score that incorporates recipient and donor variables to predict 1 . year mortality in the current era of lung transplantation. J Heart Lung Transplant. 2015:34:1449-54.

9. Cole SR, Hernan MA. Adjusted survival curves with inverse probability weights. Comput Methods Programs Biomed. 2004;75:45-9.

10. Diamond JM, Lee JC, Kawut SM, Shah RJ, Localio AR, Bellamy SL, et al. Clinical risk factors for primary graft dysfunction after lung transplantation. Am J Respir Crit Care Med. 2013;187:527-34.

11. Christie JD, Sager JS, Kimmel SE, Ahya VN, Gaughan C, Blumenthal NP, et al Impact of primary graft failure on outcomes following lung transplantation. Chest. 2005; 127:161-5.

12. Christie JD, Kotloff RM, Ahya VN, Tino G, Pochettino A, Gaughan C, et al. The effect of primary graft dysfunction on survival after lung transplantation. Am J Respir Crit Care Med. 2005;171:1312-6.

13. Christie JD, Carby M, Bag R, Corris P, Hertz M, Weill D, et al. Report of the ISHLT Working Group on Primary Lung Graft Dysfunction part II: definition. A consensus statement of the International Society for Heart and Lung Transplantation. J Heart Lung Transplant. 2005;24:1454-9.

14. Barr ML, Kawut SM, Whelan TP, Girgis R, Bottcher H, Sonett J, et al. Report of the ISHLT Working Group on Primary Lung Graft Dysfunction part IV: recipient-related risk factors and markers. J Heart Lung Transplant. 2005;24 1468-82.

15. Silliman CC, Paterson AJ, Dickey WO, Stroneck DF, Popovsky MA Caldwell SA, et al. The association of biologically active lipids with the development of transfusion-related acute lung injury: a retrospective study. Transfusion 1997;37:719-26.

Key Words: lung transplantation, blood transfusion 


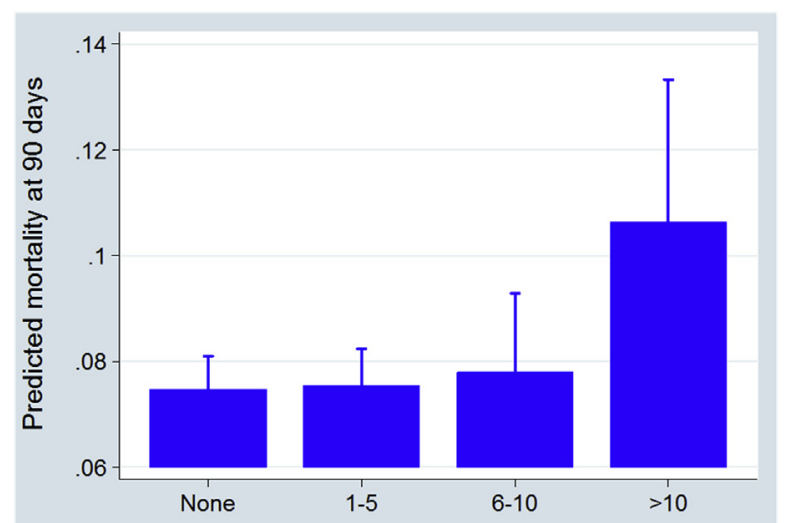

Number of units transfused during terminal hospitalization

FIGURE E1. Plots of 90-day mortality risk of transplant recipients when given lungs from donors who have received no blood, 1 to 5 units, 6 to 10 units, and $>10$ units of blood. Bars depict predicted mortality by blood transfusion with $95 \%$ confidence intervals. Comparisons among groups demonstrated a significant difference in risk between the no-transfusion group and the $>10$ units group $(P=.02)$, all other comparisons were not significant. Based on Organ Procurement and Transplantation Network data as of September 5, 2014.

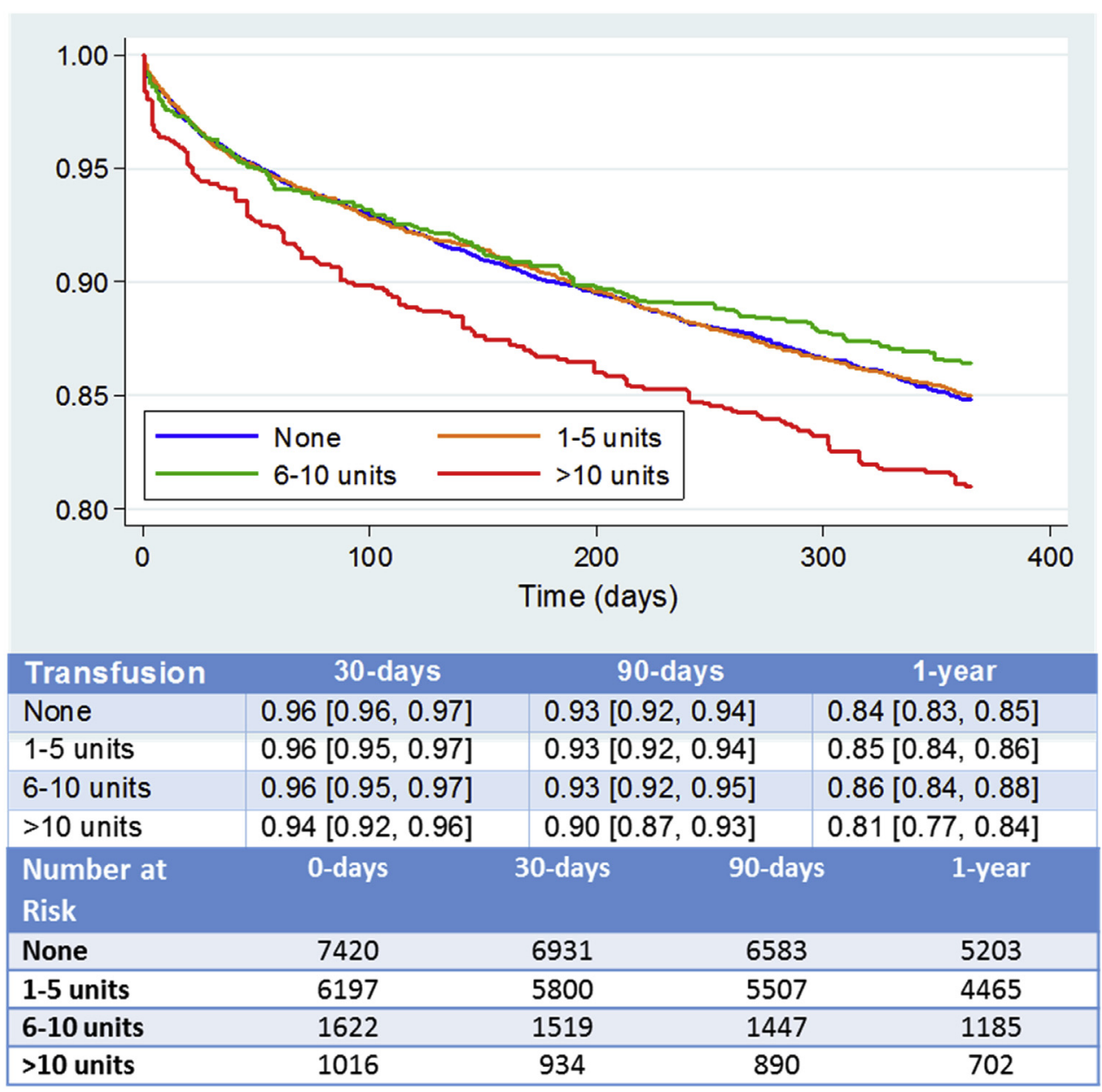

FIGURE E2. Propensity-matched survival analysis by donor transfusion status. Depicted is the inverse probability-weighted survival analysis of blood transfusion with discrete 30-day, 90-day, and 1-year mortality point estimates and confidence intervals with corresponding number at risk. There are no significant differences between groups $(P=.09)$. Based on Organ Procurement and Transplantation Network data as of September 5, 2014. 
TABLE E1. Mechanisms of donor death and number of blood transfusions

\begin{tabular}{|c|c|c|c|c|c|}
\hline & \multirow[b]{2}{*}{ n $(\%)$} & \multicolumn{4}{|c|}{ Number of transfusions (units) } \\
\hline & & $\mathbf{0}$ & $1-5$ & 6-10 & $>10$ \\
\hline Trauma & $7516(46.2)$ & $1758(10.8)$ & $3455(21.3)$ & $1396(8.6)$ & $907(5.6)$ \\
\hline Blunt injury & $4316(26.6)$ & $1020(6.3)$ & $2039(12.5)$ & $775(4.8)$ & $482(3.0)$ \\
\hline GSW & $3164(19.5)$ & $737(4.5)$ & $1404(8.6)$ & $617(3.8)$ & $406(2.5)$ \\
\hline Stab & $36(0.2)$ & $1(0.01)$ & $12(0.07)$ & $4(0.02)$ & $19(0.1)$ \\
\hline $\mathrm{ICH} /$ stroke & $5931(36.5)$ & $3818(23.5)$ & $1872(11.5)$ & $162(1.0)$ & $79(0.5)$ \\
\hline Cardiovascular & $904(5.6)$ & $555(3.4)$ & $316(1.9)$ & $24(0.1)$ & $9(0.0006)$ \\
\hline Drug intoxication & $613(3.8)$ & $459(2.8)$ & $146(0.9)$ & $22(0.0001)$ & $6(0.0004)$ \\
\hline Asphyxiation & $468(2.9)$ & $327(2.0)$ & $130(0.8)$ & $11(0.1)$ & $0(0)$ \\
\hline Natural causes & $237(1.5)$ & $159(1.0)$ & $72(0.4)$ & $5(0.0003)$ & $1(0.00006)$ \\
\hline Seizure & $173(1.1)$ & $115(0.7)$ & $54(0.3)$ & $4(0.0002)$ & $0(0)$ \\
\hline Drowning & $53(0.3)$ & $32(0.2)$ & $20(0.1)$ & $1(0.00006)$ & $0(0)$ \\
\hline Electrical & $6(0.04)$ & $3(0.0002)$ & $2(0.0001)$ & $0(0)$ & $1(0.00006)$ \\
\hline SIDS & $1(0.01)$ & $0(0)$ & $0(0)$ & $1(0.00006)$ & $0(0)$ \\
\hline Other & $353(2.2)$ & 194 (1.2) & $130(0.8)$ & $16(0.1)$ & $13(0.1)$ \\
\hline Total & 16,255 & $7420(45.6)$ & $6197(38.1)$ & $1622(10.0)$ & $1016(6.3)$ \\
\hline
\end{tabular}

Based on Organ Procurement and Transplantation Network data as of September 5, 2014. GSW, Gunshot wound; ICH, intracerebral hemorrhage; SIDS, sudden infant death syndrome.

TABLE E2. Sensitivity analysis of early mortality risk based on transplant status

\begin{tabular}{|c|c|c|c|c|}
\hline & \multicolumn{2}{|c|}{ Inclusive } & \multicolumn{2}{|c|}{ Retransplant excluded } \\
\hline & OR $(95 \%$ CI $)$ & $P$ value & OR $(95 \%$ CI $)$ & $P$ value \\
\hline \multicolumn{5}{|c|}{ 30-d mortality } \\
\hline \multicolumn{5}{|c|}{ No. of transfusions (units) } \\
\hline 0 & Reference & - & Reference & - \\
\hline $1-5$ & $1.04(0.87-1.26)$ & .66 & $1.04(0.85-1.26)$ & .70 \\
\hline $6-10$ & $1.05(0.76-1.44)$ & .79 & $0.99(0.71-1.39)$ & .95 \\
\hline$>10$ & $1.54(1.04-2.30)$ & .03 & $1.56(1.03-2.37)$ & .04 \\
\hline
\end{tabular}

The inclusive model adjusts for recipient diagnostic group, LAS, recipient BMI, ischemic time, era, pulmonary infection, chest radiograph result, and right bronchoscopy result and left bronchoscopy result to weight the effects of transfusion regardless for transplant status (equivalent to propensity model in text). The retransplant excluded includes the same variables but excludes all re-transplants from analysis. Based on Organ Procurement and Transplantation Network data as of September 5, 2014. OR, Odds ratio; $C I$, confidence interval; $L A S$, lung allocation score; $B M I$, body mass index. 